\title{
Ficha individual do Aprendiz Marinheiro do no Livro de Socorros (1872-1974)
}

\section{Individual file of the Mariner Apprentice in the Book of Socorros} (1872-1974)

\section{Ficha individual del Aprendiz Marinero en el Libro de Socorros (1872-1974)}

Os documentos que apresentamos aos leitores são duas fichas de aprendizes marinheiros inscritas no Livro de Socorros dos anos de 1872-1873 da Companhia de Aprendizes Marinheiros da Parahyba do Norte. Esses livros, eram uma ferramenta utilizada para anotação de informações individuais dos aprendizes marinheiros. Informações como filiação, local de nascimento, cor da pele, biótipo e despesas eram nelas registradas. Em sua maioria, os dados eram timbrados a punho por um oficial ou escrivão da Marinha. Era uma espécie diário de bordo e/ou escolar afim de prestar contas aos responsáveis pela Companhia em relação aos gastos efetuados com os aprendizes. Cada Companhia possuía seu Livro de Socorros. Essa documentação encontra-se disponível para consulta em microfilme no Arquivo da Marinha do Brasil, localizado na llha das Cobras, na cidade do Rio de Janeiro. 


\section{Ficha individual do Aprendiz Marinheiro - Livro de Socorros}

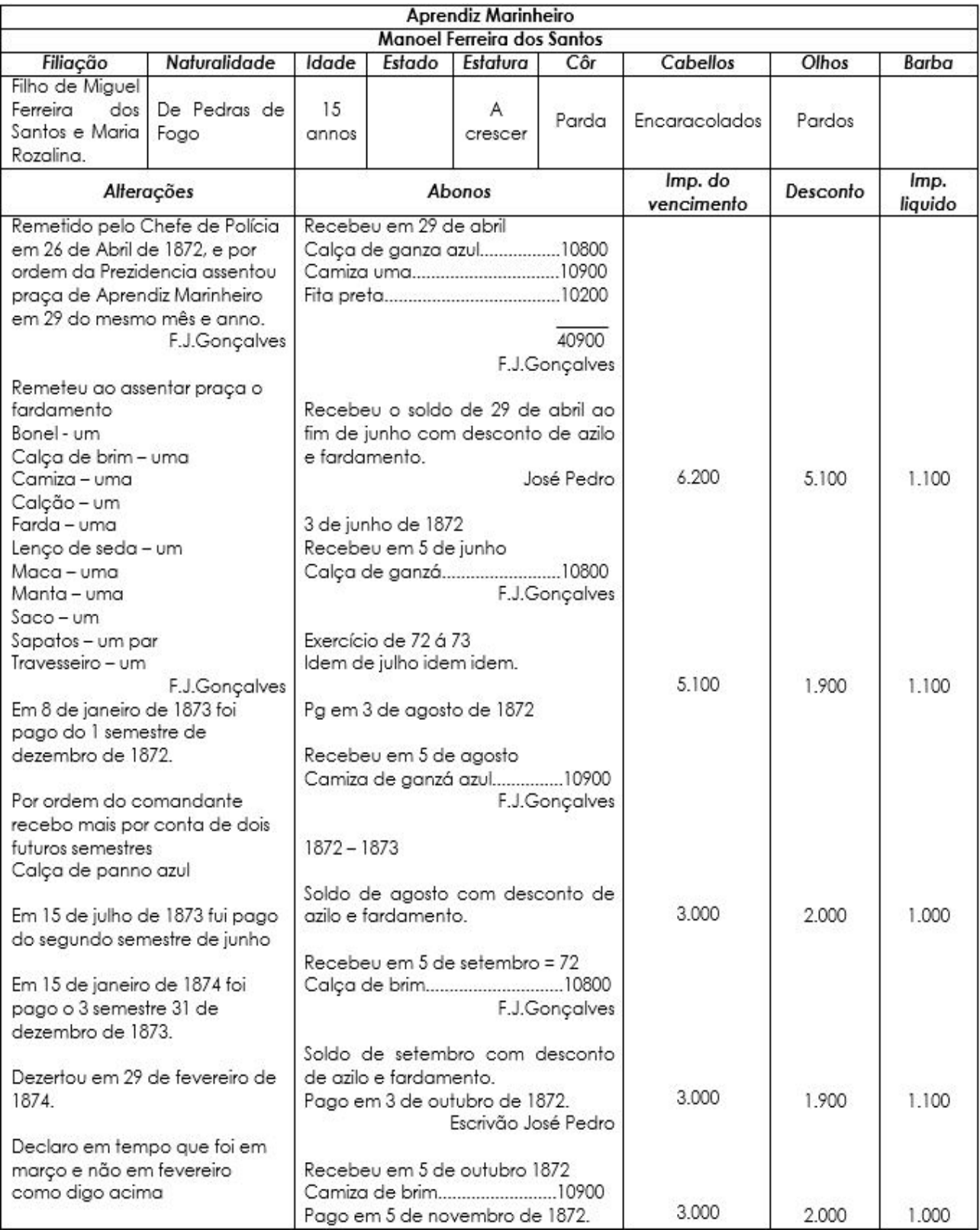




\section{Ficha individual do Aprendiz Marinheiro - Livro de Socorros (Continuação)}

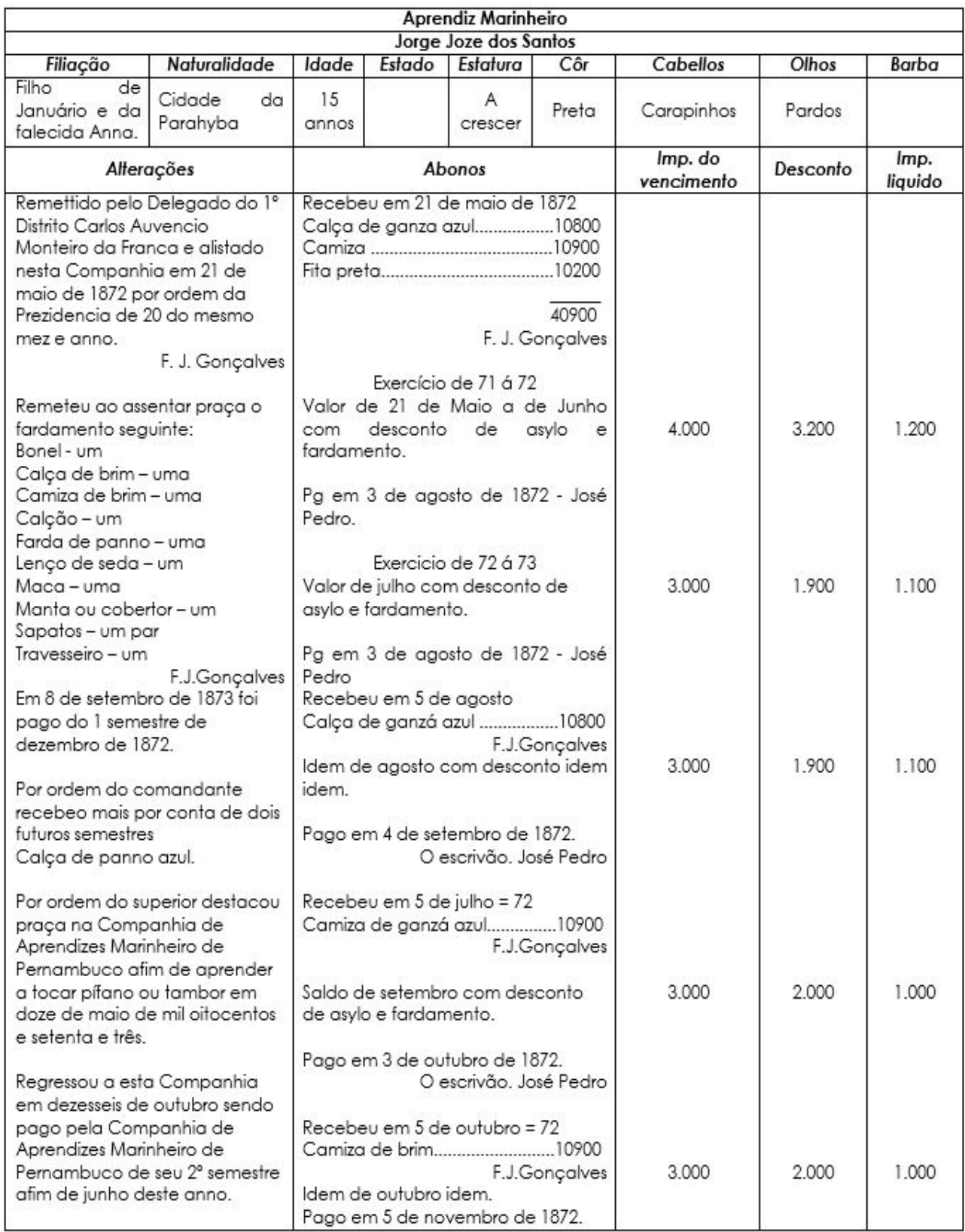




\section{Ficha individual do Aprendiz Marinheiro - Livro de Socorros (Continuação)}

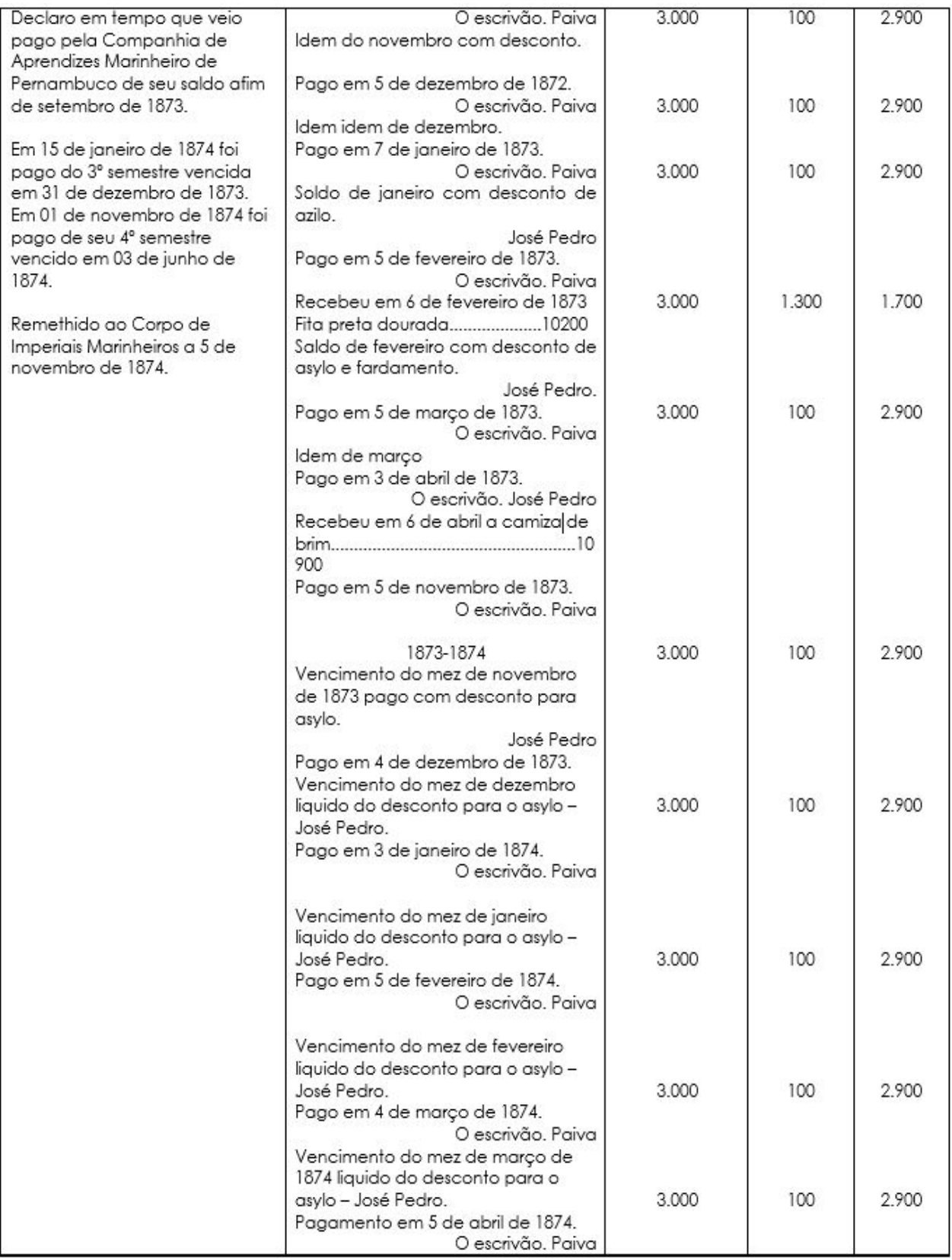


Ficha individual do Aprendiz Marinheiro - Livro de Socorros (Continuação)

encimento do mez de abril de 1874

liquido do desconto para o asylo -

José Pedro.

Pago em maio de 1874.

O escrivão. Paiva

Prof. Dr. Azemar dos Santos Soares Júnior Universidade Federal do Rio Grande do Norte (Brasil) Departamento de Práticas Educacionais e Currículo Programa de Pós-Graduação em Educação (UFRN) Programa de Pós-Graduação em História (UFCG)

Grupo de Pesquisa Estudos Histórico-Educacionais ORCID ID: https: / / orcid.org/0000-0003-001 5-415X

E-mail: azemarsoares@hotmail.com.br

$$
\text { Prof }{ }^{a} \text {. Dr }{ }^{a} \text {. Cláudia Engler Cury }
$$

Universidade Federal da Paraíba (Brasil)

Departamento de História

Programa de Pós-Graduação em Educação (UFPB)

Programa de Pós-Graduação em História (UFPB)

Grupo de Pesquisa História da Educação no Nordeste Oitocentista (UFPB) ORCID ID: https:/ / orcid.org/0000-0003-2540-2949

E-mail: claudiaenglercury73@gmail.com

Recebido 12 dez. 2018

Aceito 18 dez. 2018 